\title{
Recurrent nightmares and disorders of arousal in temporal lobe epilepsy
}

\author{
Rosalia Silvestri $^{\mathrm{a}, \mathrm{b}, *}$, Edward Bromfield $^{\mathrm{a}}$ \\ ${ }^{a}$ Department of Neurology, Harvard Medical School, Brigham and Women's Hospital, 75 Francis Street, Boston, MA 02115, USA \\ ${ }^{\mathrm{b}}$ Clinica Neurologica I Dipartimento di Neuroscienze, Scienze Psichiatriche ed Anestesiologiche, Policlinico G. Martino, \\ Università di Messina, Gazzi 98013 Messina, Italy
}

Available online 2 June 2004

\begin{abstract}
Sleep is known to be severely altered in temporal lobe epilepsy (TLE). Furthermore, sleep deprivation is one of the key factors contributing to cognitive deficits and drug resistance in TLE. In the past, "non-ictal" parasomnias, as well as parasomnia-like nocturnal episodes ultimately diagnosed as seizures, have been documented in epileptic patients. However, recurrence of possibly "ictal" parasomnias in TLE has not been adequately appreciated. Through questionnaires and diaries distributed to TLE patients and their families in a tertiary center for epilepsy, 20 out of 168 patients seen in the last 2 years have been identified as, probands and extensively recorded during sleep. Patients presented with confusional arousals were 16, 14 with nightmares, and 2 with sleep walking episodes. Episodes (25) corresponding to clinical or subclinical seizures have been video-polygraphically recorded in 10/20 patients. Therapy optimization, pharmacological or surgical, resolved the episodes in $17 / 20$ patients. A better seizure control with improved quality of life can be achieved by increasing and extending the practice of nocturnal recording in TLE patients.
\end{abstract}

(C) 2004 Elsevier Inc. All rights reserved.

Keywords: Parasomnias; Long-term monitoring (LTM); Refractory epilepsy

\section{Introduction}

Nocturnal sleep disruption is a known feature of temporal lobe epilepsy (TLE). These patients have very fragmented and superficial sleep compared to those affected by both idiopathic generalized epilepsy (IGE) and other partial epilepsies [1,9]. The overall poor sleep may contribute to memory and general cognitive impairment, which tends to be the rule even in patients without frequent seizures. Among the many night-time episodes, secondarily generalized nocturnal seizures are frequently reported [1]. We have previously reported, how most of these nocturnal episodes, whether partial or secondarily generalized, actually arise out of brief arousals from light stages of sleep [11], rather than out of sleep itself. We would now like to make the point that some of these nocturnal seizures could be misinterpreted as benign disorders of arousal [13], a common form of parasomnia, frequently encountered in adolescents, and

\footnotetext{
* Present address: Via F. Crispi 4, 98121 Messina, Italy. Tel.: +39-090-2212289; fax: +39-090-2923847.

E-mail address: rsilvestrihobson@partners.org (R. Silvestri).
}

sleep deprived subjects. Though non-epileptic disorders of arousal have been reported in epileptic children, conversely, the possible ictal nature of recurrent parasomnias in TLE has not been extensively investigated. The benign looking semi-purposeful automatic activity displayed by some of these patients could escape a more accurate diagnostic ictal interpretation in the absence of online continuous video-polygraphic monitoring. Recognizing such episodes could be crucial to diagnostic, prognostic, and therapeutic issues including, medication response, diurnal cognitive and vigilance impairment, and compliance with drug therapy. Furthermore, it could cast new light on ultradian sleep/wake-related mechanisms of seizure precipitation.

Oniroid illusions and hallucinations with strong emotional and autonomic activation have been reported to follow amygdaloid stimulation in TLE [5]. Epstein [3], suggested a possible ictal interpretation of recurrent stereotyped dreams characterized by intense fear/anxiety and feeling of dread as in the diurnal auras of TLE. Others noticed increased vividness and emotionality, as typical dream features of TLE [6]. Therefore, even recurrent nightmares in TLE could be eventually missed as subclinical nocturnal seizures. Also, 
they could give us more insight about nocturnal amygdaloid output in TLE.

\section{Materials and methods}

A sleep questionnaire and diaries have been distributed to the TLE patients of a tertiary center for epilepsy in a Harvard community hospital. Patients identified by themselves or their families as presenting with disorders of arousal or recurrent nightmares underwent long-term monitoring (LTM), with at least one full night of video-polygraphic recording. Video-polygraphic monitoring/recording was obtained by means of a BMSI 64 (32) channel recording system, including semi-automatic seizure/spike detection, over the $24 \mathrm{~h}$. Silver plate electrodes were placed on the scalp according to the international 10/20 system. LTM recordings included, polygraphic channels for detection of rapid eye movements (REMs) and submental electromyography (EMG), and bilateral sphenoidal electrodes (SP1-SP2 or T1-T2). All sleep tracings and videos were blindly and separately reviewed by three board certified electroencephalographists, with specific training in Sleep Medicine and polysomnographic scoring. Recorded episodes have been classified according to sleep stage, duration, behavioral component (motor/verbal/autonomic), electroencephalographic (EEG) pattern, and resemblance to the clinical/EEG pattern of a typical seizure. All patients had brain magnetic resonance images (MRIs) and baseline sleep deprived interictal EEG recordings. They all had a semistructured interview designed to achieve information about their premorbid and present sleep pattern, their overall day-time functioning and quality of life, and the degree of seizure-related impairment. All subjects gave their written informed consent to the study.

\section{Results}

A total of 20 consecutive patients $(6 \mathrm{M}, 14 \mathrm{~F}$; mean age 33.7 , range 16-64), were identified over a 2-year sample of 168 reviewed cases; of these 16 had confusional arousals, 14 recurrent nightmares, 2 sleepwalking and 4 night terrors, in different combinations (Table 1). Brain MRI was negative in all but six affected by mesial temporal sclerosis (MTS). Twenty-five episodes were documented in 10/20 patients: 20 confusional arousals, 3 night terrors, 1 sleep walking, and 1 nightmare out of sleep stage 2, all corresponding to ictal EEG evidence of a TLE seizure, with a mean duration of

Table 1

Parasomnias in TLE

-20 patients (6M, 14F; mean age 33.7)

-16 confusional arousals

-14 recurrent nightmares

-4 night terrors

$\bullet 2$ sleep walking
Table 2

Twenty five episodes documented by all night video-EEG monitoring in $10 / 20$ patients

-20 confusional arousals (ICAs)

$\bullet 3$ night terrors

-1 sleep walking

$\bullet 1$ nightmare (sleep stage 2)

3 min (range 1.2-3.6, Table 2). Optimization of drug regimen led to almost complete cessation of the episodes in all but the three unoperated MTS patients.

Of all episodes, ictal confusional arousals (ICAs) were the most frequent and best documented: a total of 20 episodes in 16 patients. In 5/16 patients, confusional arousals were detected by chance under LTM but neither the patients nor their relatives were aware of any previous occurrence. In those patients, who reported the disorder as occurring prior to being seen in Clinic, the mean interval between first seizure and first confusional arousal was 3.8 years (range 0-35). Patients were usually alerted to the occurrence of night-time episodes by their relatives. Upon interrogation, their memory was spotty and 10/16 could remember a sense of fear and dread similar to the aura of their day-time seizures. All episodes arose out of stage 1-2 sleep, with the exception of the two younger patients, aged 16 and 18, where ICAs appeared out of stage 3-4. Table 3 summarizes clinical/EEG features and outcome of seven patients who underwent presurgical LTM.

ICAs had a dominant motor pattern (reaching out, pulling electrodes, tossing in bed) in $3 / 10$ patients, a verbal component in $4 / 10$, were minimally symptomatic, almost subclinical/electrographic in 4/10. Out of 16 patients, 12 had strictly unilateral anterior-mesial temporal interictal epileptiform discharges (IEDs), predominantly activated by sleep, 4 had independent bitemporal IEDs. Confusional arousals were ipsilateral and EEG-wise similar to the majority of their seizures in $8 / 10$ of the patients whose sleep episodes were recorded. In one patient recorded by LTM (\#3 of Table 1) ICAs were not lateralizing (Fig. 1a and b) compared to his typical seizures.

Nightmares in 14 subjects were reported as dejà vu experiences with intense negative emotional valence. Feelings of unmotivated dread and fear, similar to diurnal auras, were common. Dream reports were spotty and confused, short in length and poorly detailed. Sleep was fragmented and unrefreshing and several other parasomnias were frequently reported, including, sleep inertia (4/14) and confusional arousals (9/14). Patients (7/14) had migraine and 6/14 had mood and/or anxiety disorders, which had started only after several months of nightmare recurrence. Some of these patients underwent phase I LTM and several ICAs were detected. No ictal nightmares were ever recorded during REM. A "nightmare" out of stage 2 sleep following partial sleep deprivation was elicited and recorded in one patient (Fig 2a and $b$ ).

All 20 patients reported various degrees of sleep disruption dating more or less to the onset of their nocturnal 
Table 3

Clinical/EEG features and outcome of seven patients who underwent presurgical LTM

\begin{tabular}{|c|c|c|c|c|c|c|c|c|}
\hline \# & PT & $\begin{array}{l}\text { Gender/ } \\
\text { age }\end{array}$ & MRI & Surgery & $\begin{array}{l}\text { Outcome/ } \\
\text { pathology }\end{array}$ & IEDs & $\begin{array}{l}\text { Nocturnal seizures on } \\
\text { LTM }\end{array}$ & $\begin{array}{l}\text { Surgical } \\
\text { complications }\end{array}$ \\
\hline 1 & $\mathrm{RM}$ & $\mathrm{M} / 32$ & NL & $\begin{array}{l}\mathrm{L} \text { temp } \\
\text { lobectomy }\end{array}$ & $\begin{array}{l}\text { II L/temp } \\
\text { subcortical } \\
\text { hypercellularity }\end{array}$ & $\begin{array}{l}\text { SP1 F7 only during } \\
\text { sleep }\end{array}$ & $\begin{array}{l}2 \mathrm{cps}, 1 \text { confusional } \\
\text { arousal }\end{array}$ & None \\
\hline 2 & PS & $\mathrm{F} / 31$ & L MTS & $\begin{array}{l}\mathrm{L} \text { temp } \\
\text { lobectomy }\end{array}$ & I hippo/gliosis & Independent SP1/SP2 & 2 confusional arousals & Paranoid psychosis \\
\hline 3 & JW & $\mathrm{M} / 34$ & L MTS & N/A & N/A & T3 only during sleep & $\begin{array}{l}1 \mathrm{cps}, 3 \text { confusional } \\
\text { arousals }\end{array}$ & N/A \\
\hline 4 & JO & $\mathrm{F} / 46$ & R MTS & $\begin{array}{l}\mathrm{R} \text { temp } \\
\text { lobectomy }\end{array}$ & I hippo/gliosis & $\begin{array}{l}\text { T4 SP2 with REM } \\
\text { activation }\end{array}$ & 1 confusional arousal & $\begin{array}{l}\text { L hemiparesis/ } \\
\text { hemianopsia with } \\
\mathrm{R} \text { occipital infarct }\end{array}$ \\
\hline 5 & $\mathrm{TS}$ & $\mathrm{M} / 38$ & R MTS & $\begin{array}{l}\mathrm{R} \text { temp } \\
\text { lobectomy }\end{array}$ & I hippo/gliosis & T4 SP2 sleep activated & 1 confusional arousal & None \\
\hline 6 & RH & $\mathrm{M} / 37$ & NL & N/A & N/A & $\mathrm{T} 4>\mathrm{T} 3$ & 5 confusional arousals & N/A \\
\hline 7 & $\mathrm{RM}$ & $\mathrm{M} / 64$ & R MTS & N/A & N/A & T4 SP2 sleep activated & 1 confusional arousal & N/A \\
\hline
\end{tabular}

$\mathrm{M}-$ male; F-female; NL—normal; L—left; R—right; MTS—mesial temporal sclerosis; temp—temporal; hippo-hippocampal; cps-complex partial seizures; IEDs-interictal epileptiform discharges.

episodes. They all had various degrees of attention/memory impairment, usually mild to moderate. Their day-time functioning was generally fair, but never in the high range. There were no complaints about vigilance. They all perceived their subjective memory impairment as worse, since the beginning of their night-time disruptive episodes. patients who underwent LTM (4/7), had temporal lobectomy (Table 3) and met Engel's criteria for class I (three patients) or class II (one patient) post-operative staging [2], after a mean follow-up of 18 months. Despite, several polytherapeutic drug trials, rare seizures, including ICAs, persisted in three patients with MTS who did not undergo surgery. Episodes were well controlled by increasing therapeutic compliance in all MRI negative patients; their regimen involved carbamazepine, gabapentin, lamotrigine, and divalproex, in various combinations.

\section{Discussion}

Despite the fact that the occurrence of ictal parasomnias could not be electrographically confirmed in all our patients, the fact that they started coincidentally or after the first seizure occurrence and then went into remission after successful therapy is in favor of an ictal interpretation of their origin. These benign looking subclinical episodes occurring at night-time could certainly mystify the epileptologist and be missed as a clue to their primary diagnosis if they happened to be coincidental with the first epileptic events. Alternatively, they might not be given consideration as a sign of ongoing seizure activity if they were associated with other long-standing epileptic seizures in older patients.

As a clue to differential diagnosis, between "true" and ictal disorders of arousals, age of onset, stage of sleep-slow wave sleep (SWS) versus light NREM sleepand activity-pattern (more confusional versus stereotyped verbal and motor patterns) could be key points. However, this distinction loses its strength when ictal disorders of arousal happen to be the heralding sign of TLE in young adolescents who maintain some of the features of "true" confusional arousals, as in the youngest subjects in our group whose ictal episodes still arose out of SWS.

Indeed, there must be a common ground for proneness to abnormal disruptive arousals from sleep, whether they are of ictal or non-ictal genesis. In fact, Tassinari et al. [12] already observed the independent occurrence of seizure and disorders of arousal in epileptic children and we have previously reported about some children who used to be sleepwalkers or have night terrors who later turned out to be diagnosed with a clear-cut epileptic syndrome [10].

Ictal disorders of arousal could also contribute to seizure resistance and to cognitive impairment through additional sleep fragmentation in the already sleep disrupted TLE population [4]. They can in fact, be seen in highly refractory epileptic syndromes, such as TLE with MTS, as well as in more benign and MRI negative TLEs where, despite a relatively low seizure frequency, some mild cognitive impairment can still be recognized.

As for recurrent nightmares, the fact that their prevalence was inversely proportional to therapy compliance in patients with refractory seizures invites their understanding as possible night-time subclinical/EEG ictal equivalents as well.

In normal subjects REM sleep is known to selectively activate blood flow in the limbic and paralimbic areas compared to wakefulness [7]. In the TLE group, this physiological mechanism could act as an "ictal promoting factor" by acutely activating flow converting the low basal interictal hypoactivity to a hyperactivity state akin to the one classically observed in the TLE ictal condition [8]. As plausible as this hypothesis might be, it would still need support from the actual detection of these episodes during REM sleep, a physiological state otherwise characterized by intense 
(n)

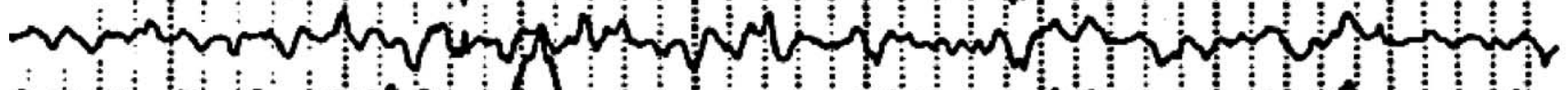
(n) mon COn (n)

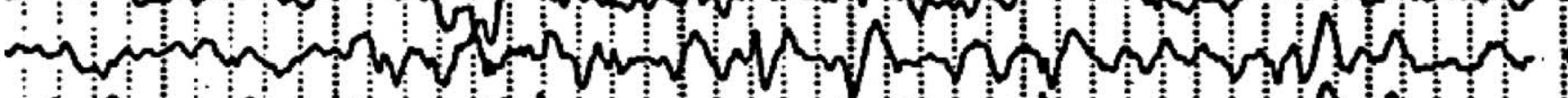
A onn (n) (1) (1) 


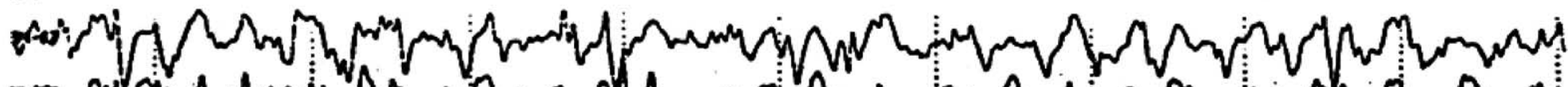

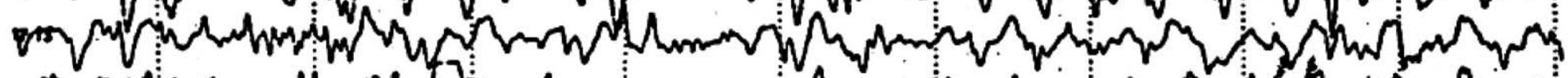
org

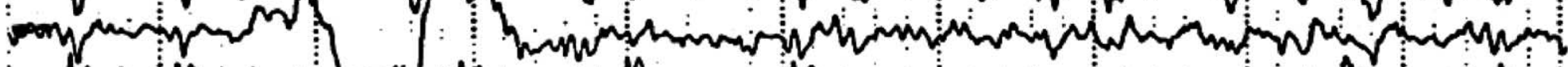

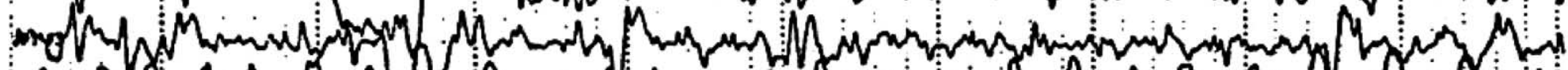
A A $P$ N W nown An Non (1)

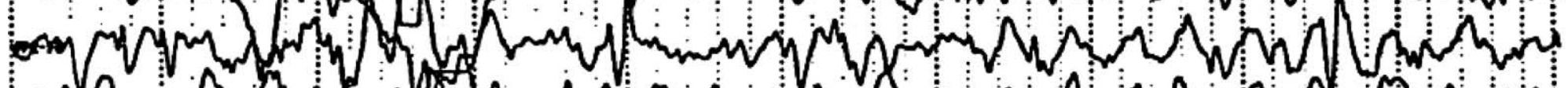
-

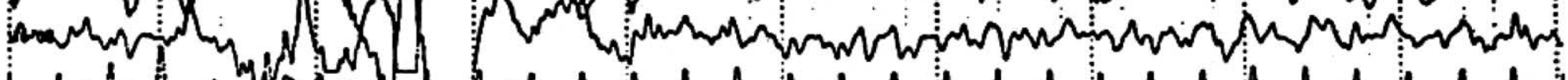

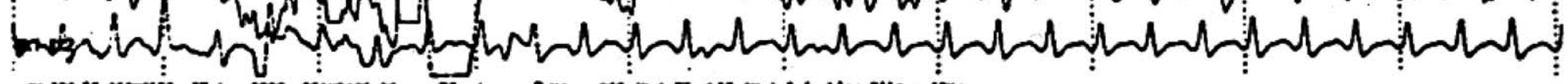




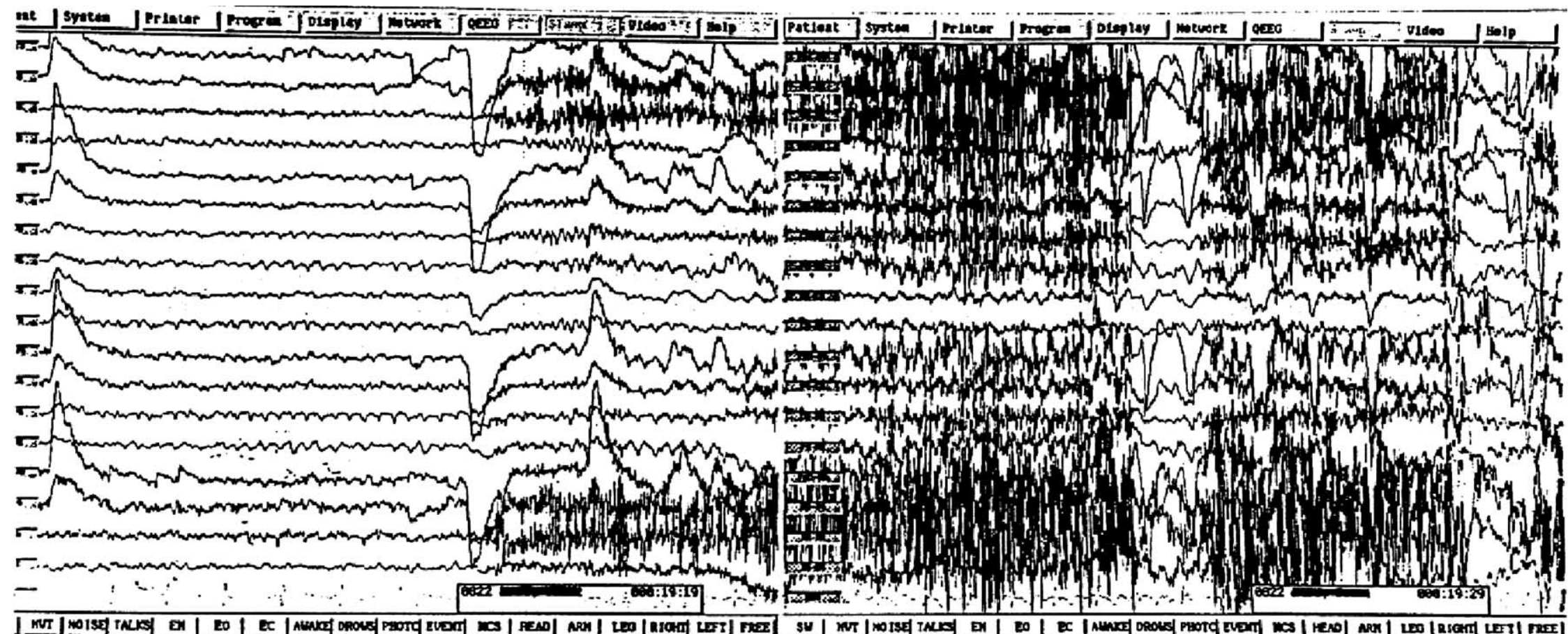

(a)

Fig. 2. (a) 19 min into sleep stage 2 of a sleep deprived recording, a run of rhythmic $5-6 \mathrm{~Hz}, 30-50 \mathrm{mV}$, $\mathrm{R}>\mathrm{L}$ temporal sharp theta is noticed, lasting $\sim 40 \mathrm{~s}$ and progressively slowing to $1-2 \mathrm{~Hz}$ delta. There is excessive movement artifact and patient sits up to say she "had one." Paper speed $30 \mathrm{~mm} / \mathrm{s}$; sensitivity $7 \mu \mathrm{V} / \mathrm{min}$. (b) Same patient. 2 min later. R anterior temporal slowing persisting $\sim 3$ min. 


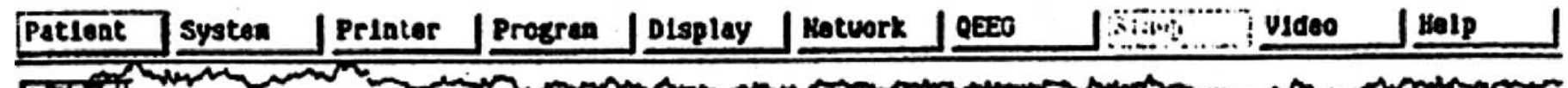

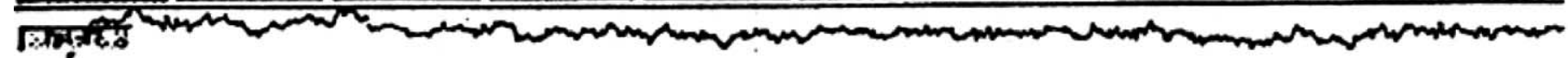

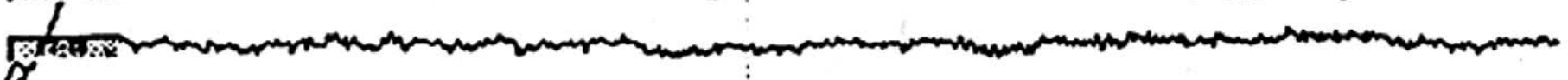
RV: Fisis

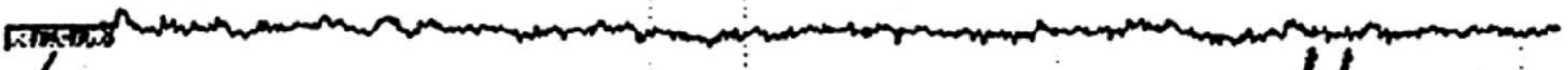

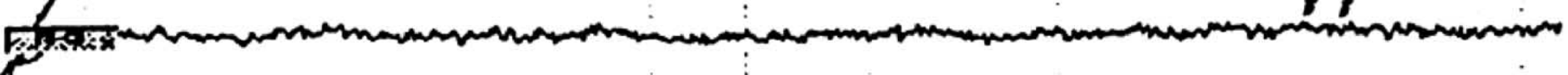

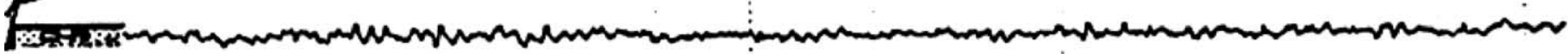

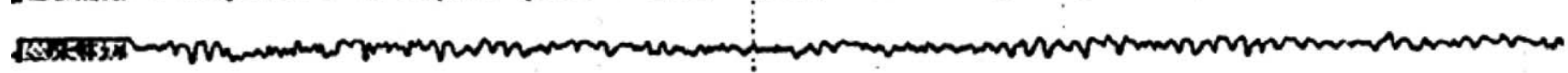

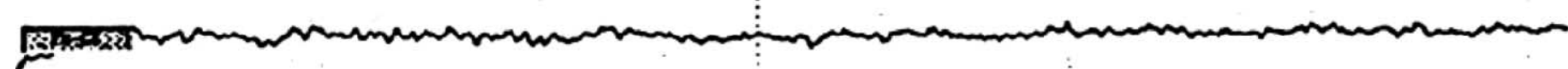
Fis; ESj pass

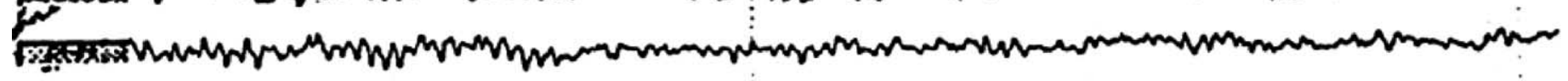

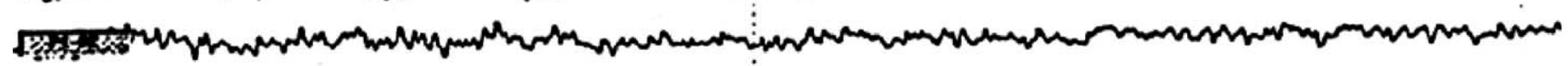

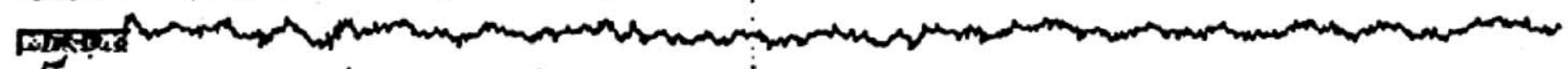

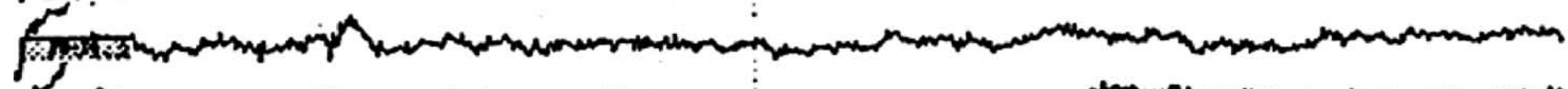

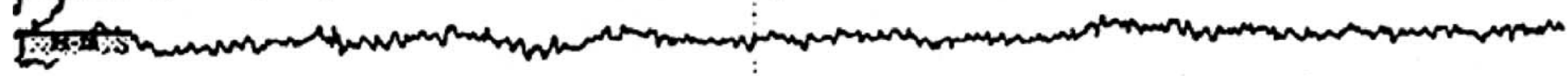

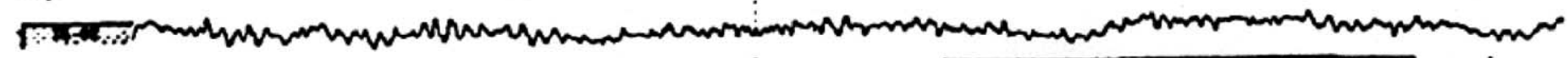

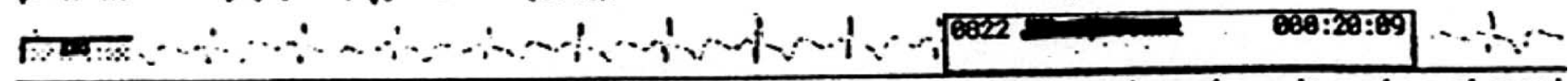

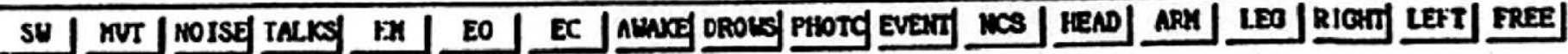


output inhibition. Against the hypothesis, is the fact that ICAs have been recorded out of NREM sleep. Some of them are accompanied by an oniroid dejà vu experience, as seen in Fig. 2a. Also, spotty recall and confused reports are typical of NREM sleep states, where the sleep-related ictal activation of drowsiness and stage shifts could still be expected to be operative. Only prolonged LTM recordings across several nights in selective patient populations, can be expected to resolve this clinical and neurophysiological dilemma.

The possibility of misinterpreting nocturnal seizures as benign parasomnias is high in TLE, leading to insufficient seizure control, misdiagnosis, and progressive cognitive impairment. An increased number of overnight recordings can be the premise for a better quality of life in these patients.

\section{References}

[1] C.W. Basil, T.S. Welczack, Effects of sleep and sleep stage on epileptic and non-epileptic seizures, Epilepsia 38 (1) (1997) 56-62.

[2] J. Engel Jr., Outcome with respect to epileptic seizures, in: J. Engel Jr (Ed.), Surgical Treatment of the Epilepsies, Raven Press, New York, 1987, pp. 553-571.

[3] A. Epstein, Dreaming and Other Involuntary Mentation, Int. University Press, Madison, 1995.
[4] G. Erba, R. Ferber, Sleep disruption by subclinical seizure activity as a cause of increased waking seizures and decreased day time function, Sleep Res. 12 (1983) 307.

[5] P. Gloor, Role of the amygdala in temporal lobe epilepsy, in: J.P. Aggleton (Ed.), The Aymgdala, Wiley-Liss, New York, 1992.

[6] I. Gruen, A. Martinez, C. Cruz-Olloa, F. Aranday, J. Calvo, Caracteristicas de los fenomenos emocionales en las ensonaciones de pacientes con epilepsia del lobulo temporal, Salud Mental 20 (1) (1997) 8-15.

[7] P. Maquet, J.M. Peters, J. Aerts, A. Laxen, G. Franck, Functional neuroanatomy of human rapid-eye-movement sleep and dreaming, Nature 383 (1996) 163-166.

[8] A.L. Rabinowicz, E. Salas, R.C. Beserra Leguarda, S.E. Vasquez, Changes in regional cerebral blood flow beyond the temporal lobe in unilateral temporal lobe epilepsy, Epilepsia 38 (3) (1994) 1011-1014.

[9] M. Sammaritano, J.M. Saint-Hilaire, Modifications of sleep organization in patients with extratemporal epilepsy, Epilepsia 38 (Suppl. 8) 1994.

[10] R. Silvestri, P. DeDomenico, G. Mento, et al., Epileptic seizures in subjects previously affected by disorders of arousals, J. Clin. Neurophysiol. Clin. 25 (1995) 19-27.

[11] R. Silvestri, A. Laganà, P. DeDomenico, et al., Diagnosi differenziale tra crisi temporali in sonno e disordini dell'arousal, in: R. DiPerri, R. Silvestri, S. Smirne (Eds.), II Sonno in Italia, Milano, Edizioni Poletto, 1994, pp. 41-45.

[12] C.A. Tassinari, D. Mancia, Della Bernardina, et al., Pavor nocturnus of non-epileptic nature in epileptic children, EEG Clin. Neurophysiol. 33 (1972) 603-607.

[13] The International Classification of Sleep Disorders. Diagnostic and Coding Manual, American Sleep Disorders Association, Rochester, USA, 1990. 